EGU21-10369, updated on 24 Feb 2022

https://doi.org/10.5194/egusphere-egu21-10369

EGU General Assembly 2021

(c) Author(s) 2022. This work is distributed under

the Creative Commons Attribution 4.0 License.

\title{
The MEDWATERICE project: Towards a sustainable water use in Mediterranean rice-based agro-ecosystems
}

\author{
Arianna Facchi ${ }^{1}$ and the MEDWATERICE Team ${ }^{*}$ \\ ${ }^{1}$ Department of Agricultural and Environmental Sciences (DiSAA), Università degli Studi di Milano, Milano, Italy \\ (arianna.facchi@unimi.it) \\ ${ }^{*}$ A full list of authors appears at the end of the abstract
}

In the Mediterranean basin, rice is cultivated over an area of $1,300,000$ hectares. The most important rice-producing countries are Italy and Spain in Europe (72\% of the EU production; 345,000 ha), and Egypt and Turkey among the extra-EU countries (almost totality of the production; 789,000 ha). Traditionally, rice is grown under continuous flooding; thus, it requires more water than non-ponded crops. On the other hand, rice is strategic for food security in some countries such as Egypt, and human consumption in the whole Mediterranean is steadily increasing.

The MEDWATERICE project (PRIMA-Section 2-2018; https://www.medwaterice.org/), which started in April 2019, aims to explore the sustainability of innovative rice irrigation methods and technologies in the Mediterranean basin, in order to reduce rice water use and environmental impacts, and to extend rice cultivation outside of traditional paddy areas to meet the growing demand. The MEDWATERICE consortium includes universities, research centres and private companies operating in the Mediterranean area (IT, ES, PT, EG, TR, IL). Case studies (CSs) are implemented in pilot farms of the countries involved in the project. Tested alternative irrigation methods and technologies adopted in each CS are being tailored to local conditions using a participatory action research approach through the establishment of Stake-Holder Panels in each country, which include regional authorities, water managers, farmers' associations and consultants, and private companies of the rice production chain. Irrigation strategies experimented in the pilot farms and compared to the continuous flooding (considered as the 'reference' irrigation method in all CSs), are: dry seeding and delayed flooding, alternate wetting and drying, lengthening of drying periods, reduction in irrigation inflow/outflow, hybrid irrigation, multi-nozzle sprinkler irrigation, surface and sub-surface drip irrigation, and waste-water reuse through sub-surface drip irrigation. For each irrigation solution, innovative technologies and the most appropriate rice varieties and agronomic practices are tested to minimize impacts of irrigation water reduction on yield quantity and quality. Data collected at the farm level are extrapolated to the irrigation district level to support water management decisions and policies. Indicators for quantitative assessment of environmental, economic and social sustainability of the irrigation options are also being defined. Outcomes produced by MEDWATERICE are expected to generate knowledge on how to improve sustainability of rice production in the countries of the 
Mediterranean area, with particular attention to the adoption of water-saving techniques.

During the conference, approaches and methodologies adopted and developed within the project, and results obtained so far will be presented, with particular attention to the experimentation conducted in the pilot farms, to the methods for the upscaling the achievements to the irrigation district scale, and to the set of indicators for quantifying economic, environmental and social sustainability of irrigation methods and technologies currently under definition.

MEDWATERICE Team: (1) A. Facchi, (1) O. Gharsallah, (2) M. Romani, (2) A. Ricciardelli, (3) M. Trevisan, (4) F. Ferrari, (4) A. Tediosi, (5) S.M.M. Shebl, (6) A.A. Aboukheira, (7) F. Ramirez de Cartagena, (7) J. Pinsach Boada, (7) G. Arbat, (8) L. Mateos, (8) H. Gómez-Macpherson, (9) C. Mira, (10) R. Yonai, (10) R. Sabarinathan, (11) J.M. Gonçalves, (11) M. Nunes, (12) I. de Lima, (12) R.G. Jorge, (13) M. Enginsu, (13) R. Unan; (1) Università degli Studi di Milano (Italy), (2) Ente Nazionale Risi (Italy), (3) Università Cattolica del Sacro Cuore (Italy), (4) Aeiforia srl (Italy), (5) Agricultural Research Centre (Egypt), (6) National Water Research Centre (Egypt), (7) Universitat de Girona (Spain), (8) Agencia Estatal Consejo Superior de Investigaciones Científicas (Spain), (9) Tepro Consultores Agrícolas SL (Spain), (10) Netafim (Israel), (11) Instituto Politécnico de Coimbra (Portugal), (12) Universidade de Coimbra (Portugal), (13) Black Sea Agricultural Research Institute (Turkey). 